\title{
Chapter 1 \\ Who Is Missing? Undercounts and Omissions in the U.S. Census
}

\begin{abstract}
Over the past 60 years, the overall accuracy of the U.S. Decennial Census has steadily improved. But some groups still experience higher net undercounts than other groups in the Census. The issue of differential Census undercounts is introduced in this Chapter along with some of the key concepts related to measuring the accuracy of Census counts, sometimes called Census coverage. Some of the key terminology is also discussed in this Chapter along with a description of the intended audience for this publication. The contents of the publication are described Chapter by Chapter.
\end{abstract}

\subsection{Introduction}

The mantra of the U.S. Census Bureau is to count every person once, only once, and in the right place. This is easy to say, but difficult to achieve. The U.S. Census Bureau tries very hard to include every person in the Decennial Census, but some people are always missed. The situation is summed up neatly by the U.S. General Accounting Office (2003, p. 4),

The Bureau puts forth tremendous effort to conduct a complete and accurate count of the nation's population. However, some degree of error in the form of persons missed or counted more than once is inevitable because of limitations in Census-taking methods.

This thought is echoed by Raymondo (1992, p. 37),

As most people know, the census of population is intended to count each and every resident of the United States. As most people might suspect, any undertaking so ambitious is bound to fall short to some degree, and the fact is that the census does not count each and every person. The failure to count everyone in the census is referred to as an undercount or, more generally as a coverage error.

The extent to which people in certain groups are missed or counted more than once is reflected in Census coverage measurements. The most widely used measures of Census coverage or Census accuracy are net undercounts, net overcounts and omissions.

What is a net undercount in the Census? In every demographic group, some people are missed in the Census, and some people are counted more than once (or included inappropriately) in the Census. When the number of people missed is larger than the 
number of people counted more than once, it produces a net undercount. When the number of people counted more than once is larger than the number of people missed it produces a net overcount. Census Bureau whole person imputations are another component in this equation, but for the sake of simplicity they are ignored for now.

Net undercounts have been measured often and consistently in the U.S. Census over the past 60 years, and it has been the main measure used by demographers to assess Census accuracy. Robinson (2010) refers to the net undercount from the Census Bureau's Demographic Analysis method as the "gold standard." A more detailed discussion of this topic is provided in Sect. 1.4 of this Chapter and in Chap. 3.

Omissions are a key component of net undercounts. Omissions reflect people who are missed in the Census and as such they are an important focus of this book. In some ways, omissions are a better measure of Census quality than net undercounts because double counting can mask omissions. A net undercount of zero could be the result of no one being missed and no one double counted, or for example, it could reflect a situation where ten percent of the population are missed, and ten percent are double counted. Differential omissions rates reflect that same kind of inequity as differential undercount rates. Data on the characteristics of people who are missed are presented in most of the Chapters in this book.

Unfortunately, people in some groups have higher net undercount rates than people in other groups. These differences in Census coverage are referred to as a "differential undercounts" and are the focus of this book. More specifically this book focuses on the groups that have the highest net undercounts and highest omissions rates in the U.S. Census.

The main point of this publication is to present existing information on net undercounts and omissions in the U.S. Census in a simple, organized, and systematic way. I have not found a single publication that pulls together key undercount and omissions data from different Census assessment methods, for many groups, over several times periods. This publication aims to fill that niche. By putting the key information into one publication I hope this publication makes key data on Census accuracy more readily available to a wider, non-technical audience. I also hope this publication facilitates further research on Census coverage issues.

By focusing on which groups have the highest net undercounts and Census coverage differentials the primary focus of the publication is descriptive rather than analytical. Material that tries to explain why net undercounts (or net overcounts) occur is more limited in this publication.

The book draws heavily on data produced by the U.S. Census Bureau. Most of the statistics presented here are publicly available, but the key data are often buried in large statistical reports, available on some obscure portion of the Census Bureau's website, appear only in scholarly journals, in presentations made at scientific conferences, or appear in internal Census Bureau reports (see, for example, U.S. Census Bureau 1974, 2012; Fay et al. 1988; Robinson et al. 1993; Robinson and Adlaka 2002; Mayol-Garcia and Robinson 2011). In some cases, one must download and analyze data files from the Census Bureau to produce simple net undercount tabulations. For a large share of the public such information is not easily or readily available. 
More specifically, this report will draw extensively on data produced by the Census Bureau's Demographic Analysis (DA) and Dual-Systems Estimates (DSE) programs. More information about these two methods is provided in Chap. 3.

Although Demographic Analysis and Dual-Systems Estimates are the best estimates available regarding Census coverage it is important to recognize these methods have some limitations. For example, the demographic groups for which these two programs produce data are limited. Census Bureau tabulations have focused on measuring Census coverage for five demographic characteristics including;

- Age

- Sex

- Race

- Hispanic Origin Status

- Tenure

The 2010 DSE reports covers all these characteristics and the 2010 DA covers all but tenure, at least to some degree.

It should be noted that many times the most important differential undercounts are based on a combination of the characteristics noted above. For example, the net undercount for Black males age 30-49 is much higher than the net undercount rate for the total Black population or total male population. These special populations will be highlighted in the appropriate Chapters.

The characteristics noted above are important, but there are many other groups for which we would like to have data on Census undercounts. Many such groups are highlighted in public discussion of the Census. For example, in response to release of 2010 Census results, former Undersecretary of Commerce Dr. Rebecca Blank (2012, p. 1) said,

However, as has been the case for some time, today's release shows that certain populations were undercounted. More work remains to address persistent causes of undercounting, such as poverty, mobility, language isolation, low levels of education, and general awareness of the survey.

Undercounts for the groups mentioned by Dr. Blank are not measured by the Census Bureau's DA or DSE methods. Some of these groups are captured by the "hardto-count" factors (Bruce and Robinson 2003) and Mail Return Rates (Letourneau 2012) used by the Census Bureau and Census advocates. To be clear, this publication focuses on direct measures of Census coverage (net undercounts, net overcounts, and omissions) rather than metrics that reflect likelihood of being counted accurately like Mail Return Rates or hard-to-count scores.

In addition to reports and datasets from DA and DSE, I will add information from Census Bureau reports focused on some Census operations. Information on Census operations can shed light on the mechanisms by which differential Census undercounts occur. For example, see U.S. Census Bureau reports on topics such as Census Followup, Non-Response Followup, and Mail Return Rates (Govern et al. 2012; Letourneau 2012). I also draw on a series of qualitative studies that can help 
us understand why Census errors occur (de la Puente 1993; Schwede 2003, 2006; Schwede and Terry 2013).

The focus of this report is on Census net undercounts and omissions, but it should be noted that these are not the only types of Census errors. Census errors also include net overcounts and erroneous inclusions. Erroneous inclusions are people who are counted more than once and people who are included in the U.S. Census inappropriately. For example, an erroneous inclusion would be a foreign tourist who gets included in the Census by mistake or someone who dies before the Census date but is included inappropriately in the Census count. Another type of error is counting people in the wrong place.

From a scientific perspective net overcounts and erroneous inclusions are measurement errors just like net undercounts and omissions. But net undercounts and omissions are a much bigger public relations and public perception problem. According to Williams (2012, p. 8), "Differential undercounts are a recurrent problem in the Decennial Census and diminish the perception that the count is equitable to the entire population."

Net undercounts and omissions are much more of a problem than net overcounts. I am not aware of any lawsuit brought by a state or city because of real or perceived net overcounts, but there have been many lawsuits brought because of real or perceived net undercounts. Undercounts are also much more of a public relations problem for the Census Bureau. Note in the previous quote from Dr. Blank, she focuses on the problem of undercounts in the Census, not overcounts. Given this situation this book will focus on net undercounts and omissions with only passing note on net overcounts or erroneous inclusions.

\subsection{Audience}

This book is aimed largely at people outside the scholarly community such as practitioners and advocates. Because of the social equity issues raised by the differential net undercounts for many racial and Hispanic minority groups the book will be of interest to many civil rights organizations such as the Leadership Conference on Civil Rights, National Association of Latino Elected Officials, the Mexican-American Legal Defense and Education Fund, The National Urban League, The National Association for the Advancement of Colored People, Asian-American Advancing Justice League, National Congress of American Indians, and many others. One of the main purposes for writing this book is to make the high-quality data on Census errors available to a wider audience. Too many times, I have heard people assert that there is a net undercount for this group or that group when there is no good evidence to support that claim.

The book may also be useful for researchers in the demographic community because it fills an important niche regarding Census accuracy. It will provide a handy reference for the relative Census coverage rates for many key populations. In the context of scholarship, the book will help round out the literature in demography and/or 
population studies courses. Since the publication provides a lot of information in one place it could be a useful reference book for Census Bureau staff and related government organizations such as the U.S. General Accountability Office, The Congressional Research Service, and The U.S. Office of Management and Budget. Other possible users include professional organizations that monitor the Census such as the Population Association of America, the American Statistical Association, American Association of Public Opinion Researchers, and the non-profit organizations such as Population Reference Bureau, The Funders Census Initiative, and The Census Project.

Given this audience, some of the more detailed and esoteric aspects of the statistical methods used to assess Census coverage are ignored in favor of more straightforward language and a focus on results rather than methods. Readers who are more technically inclined can find the more detailed information through the citations offered in this publication, and the readers who are not technically inclined will get the basic information.

A significant segment of the audience for this book will be focused on one group or one Chapter. For example, the National Association for the Advancement of Colored People are likely to focus on the Chapter related to Blacks and the National Association for Latino Elected Officials are likely to focus on the Chapter related to Hispanics. Partnership for America's Children will be more interested in the Chapter on age which shows a high net undercount of young children.

\subsection{Terminology}

Some of the language, terminology, and nomenclature used in this publication may be unfamiliar to many readers and some terms have been used inappropriately or incorrectly in the past. In addition, some of the key terms may sound like the same thing but they have a different meaning to demographers. In general, I follow the nomenclature conventions of the U.S. Census Bureau.

The terms "net undercount" and "net overcount" have very precise meanings to demographers. But the terms "undercount" or "net undercount" are sometimes used loosely by non-demographers to mean people missed in the Census in a broad sense. In this publication the focus is on scientific measurements of net undercounts.

It is important to recognize that the net undercount does not reflect the number of people missed even though the term undercount is often used to suggest this. As stated earlier, net undercounts reflect a balance of people missed and people counted more than once or otherwise included erroneously. Demographers use the terms gross undercount or omissions to reflect the number of people missed.

Only the Dual-Systems Estimates (DSE) method produces data for omissions. I use omissions in many portions of this publication to supplement data on net undercounts. A more detailed discussion of methodology is offered in Chap. 3.

Prior to the 2010 Census, whenever the Census count was less than the DA estimate the Census Bureau typically reported the difference between a DA estimate and the 
Census as an undercount. But some of the information put out by the Census Bureau following the 2010 Census refers to differences between the Census count and the DA estimates rather than net undercounts or net overcounts. This is meant to reflect the fact that both the Census and the estimate to which the Census is being compared (DA or DSE) have errors. While I understand the intent of using the term "differences" rather than undercount and overcounts, I will use the traditional terms net undercount and net overcount because these terms are more widely understood, and they indicate the directionality of the differences which makes communication more efficient. In other words, saying there is a one percent difference between the Census count and the Demographic Analysis (DA) estimate does not tell a reader if the Census is larger or smaller than the DA estimate, but saying there is a one percent net undercount indicates the Census count is lower than the DA estimate.

Another issue that might cause confusion is the fact that undercounts have sometimes been reported as a negative number by the Census Bureau (Velkoff 2011) and sometimes as a positive number by the Census Bureau (U.S. Census Bureau 2012). Since I draw on Census Bureau reports that use both expressions for net undercounts, I thought it important to standardize presentation within this publication. In the remainder of this publication, the differences between the Census counts and DA or DSE estimates are shown as the Census count minus the DA or DSE estimate. So, a negative number reflects a net undercount. This is consistent with the convention used by Velkoff (2011) in reporting the first results of the 2010 DA. This presentation style was also used in a couple of recent Census Bureau papers on this topic (King et al. 2018; Jensen et al. 2018). Also, this approach is consistent with O'Hare (2015) reporting on the undercount of young children. This calculation is sometimes labeled "net Census coverage error" in other research. In this publication, a negative number consistently implies a net undercount and a positive number implies a net overcount. I chose to use the net Census coverage error construction because I feel having an undercount reflected by a negative number is more intuitive.

When figures are stated in the text as an undercount or an overcount, the positive and negative signs are not used. In converting the difference between Census counts and Demographic Analysis or Dual-Systems Estimates to percentages the difference is divided by the DA or DSE estimate not the Census figure.

Another point of potential confusion is the name applied to the Dual Systems Estimation method. The DSE has been called by different names in the past three Censuses. In the 1990 Census it was called the Post-Enumeration Survey (PES), in the 2000 Census it was called Accuracy and Coverage Evaluation (A.C.E.) and in the 2010 Census it was called Census Coverage Measurement (CCM). In the 2020 Census, this method will again be called the Post-Enumeration Survey or PES (U.S. Census Bureau 2017b). I use the term DSE for consistency. 


\subsubsection{Net Undercounts, Omissions, and Hard-to-Count Populations}

Another term that is related to net undercounts or Census omissions is "hard-tocount" populations. Many closely related terms (hard-to-count areas, hard-to-count populations, difficult to enumerate populations, and hard-to-survey populations) have been used almost interchangeably (Tourangeau et al. 2014). Census Bureau (2017a) also uses the term "Hard-to-Reach" populations to identify groups that are difficult to enumerate accurately.

The U.S. Census Bureau (2017a, p. 2) defines hard-to-count populations as,

Hard-to-count populations face physical, economic, social, and cultural barriers to participation in the Census and require careful consideration as part of a successful communications strategy.

While this is a good conceptualization of "hard-to-count" populations, it does not specify how to measure the concept and it does not mean that hard-to-count groups necessarily are undercounted in the Census. Generally, groups that have a significant net undercount are thought of as hard-to-count groups, but not all hard-to-count groups have measurable net undercounts in the Census.

Many of the hard-to-count populations not covered by DA and DSE can be addressed to some level by identifying who lives in hard-to-count neighborhoods (O'Hare 2015). In addition, Mail Return Rates are often used as a proxy for Census coverage (Letourneau 2012; Word 1997; Erdman and Bates 2017). A set of hard-tocount factors were provided by Bruce and Robinson (2003) in the mid-1990s that are sometimes used to identify vulnerable populations. Following the 2010 Census the Census Bureau produced a new metric for identifying hard-to-count areas which is called the Low-Response Score (Erdman and Bates 2017).

But it is important to note that hard-to-count factors, Low-Response Scores, and Mail Return Rates (Bruce and Robinson 2003; Erdman and Bates 2017) are not measures of Census coverage per se. Moreover, the association between Mail Return Rates and net undercounts are not always clear. O'Hare (2016, p. 51) shows that only five of thirteen groups concentrated in neighborhoods with low Mail Return Rates had a net undercount rate that was statistically significantly different than zero.

\subsection{Perspectives on Differential Undercounts}

Differential undercounts suggest comparisons between the coverage rate of one group and the coverage rate of another group. But sometimes it is not clear what the appropriate comparison group should be and sometimes data for the appropriate comparison group are not available. For example, if one is looking at the net undercount rate for young children, should that undercount rate be compared to the net undercount rate for the total population, the net undercount rate for some age-group of adults, or the net undercount rate for the elderly? 
Other times, there is no net undercount measurement for the group one would like to use as a comparison group. For example, for the 2010 DA undercount estimates, there are no estimates for the White population or the Non-Hispanic White population. So, demographers often compare Census coverage of the Black population to the Non-Black population. Demographers sometimes end up making comparisons that may not be the most appropriate ones from a conceptual point of view but are dictated by the data available.

Comparing all net undercount rates to the net undercount rate for the total population would provide one constant benchmark, but it would often overlook crucial differences between groups. For example, from a social justice point of view, the difference between the net undercount rate of Blacks and Non-Hispanic Whites is probably more meaningful than the difference between net undercount rates of Blacks and the total population. Keep in mind the total population includes many other hard-to-count groups besides Blacks.

If this publication were only focused on one group, the appropriate comparison group might be easy to identify. But the net undercounts and net overcounts for many groups are compared in this book. Therefore, I focus on identifying groups with high net undercount or omissions rates even if there is not a specific comparison group. One point of this book is giving readers a good sense of which groups have the highest net undercounts and omissions rates in the U.S. Census.

\subsection{Contents of This Book}

Following this Introductory Chapter, I provide a Chapter on the uses of Census data. It is difficult to understand the importance of Census accuracy unless one understands how Census data are used in the public and private sectors. Census undercounts are important because data accuracy is linked to many equity and social justice issues. In addition, Census undercounts are one of the biggest Census Bureau public relations issues. With respect to Census undercounts Kissam (2017, p. 797) states, "These persistent undercounts raise difficult questions about why it occurs and are troubling due to their practical implications for the conduct of public policy."

In Chap. 3, I describe the key methods used by the Census Bureau to assess accuracy in the Decennial Census. The descriptions offered here are relatively parsimonious with citations provided for readers who would like more detailed information on this topic. The strengths and limitations of each method are also noted.

In Chap. 4, I provide a summary of key undercount differentials based on age, sex, race, Hispanic Origin, and tenure. This Chapter is meant to give readers an overview of Census undercounts and provide a framework and a foundation for several later Chapters. In Chap. 4, information is also presented on some of the key groups not reflected in the Census Bureau's DA or DSE data.

The next several Chapters focus on specific demographic characteristics. I present the groups in the order in which the questions appear in the Census questionnaire. 
In Chap. 5, I examine undercount differentials by age. The major points here are the very high net undercount of young children and the net overcounts of young adults and the older population (age 60 plus). In Chap. 6, I explore differences by sex, which shows, on average, males have a net undercount while females have a net overcount.

In Chaps. 7 through 11, I explore differentials in Census accuracy by major race/Hispanic Origin groups (Hispanics, Blacks, Asians, American Indians/Alaskan Native, and Native Hawaiian/Pacific Islander). Researchers differ in their views about the appropriateness of using race and Hispanic Origin as a lens for differential undercounts. Some feel differences by race should not be the focus of attention because racial differences in net undercounts are simply a product of other nonracial factors and we should be focused on these other more dominant non-racial factors. For example, Schwede et al. (2014, p. 293) state,

Though there is no reason to believe that race or ethnicity in and of itself leads to coverage error, it seems that some underlying variables associated in past studies with undercounting may also be correlated with race (e.g., mobility, complex living situations, and language isolation).

In other words, race is widely seen as a proxy for a combination of factors related to the likelihood of being missed in the Census.

Nonetheless there are least three reasons for looking at differential Census coverage through the lens of race and Hispanic Origin. First, at least from a civil rights perspective, differential undercounts among minority groups is a central problem with the Decennial Census results and many of the most pronounced differentials occur among different race groups. Second, there is a wealth of data related to Census coverage by racial categories. Examination of net undercounts by race is a very prominent facet in much of the previous work on differential undercounts. Third, several analyses show that race is still a salient factor even after many of the other factors are controlled (Erdman and Bates 2017; Fernandez et al. 2018).

Readers may also note that there is no Chapter on the White or Non-Hispanic White population. The White population is seldom discussed in the context of Census undercount because the Whites are almost always counted more accurately than their counterparts in racial and Hispanic minority groups. In this publication, data for the Non-Hispanic White population are provided in many Chapters as a comparison group for minority groups.

In Chap. 12, I examine Census coverage rates by tenure. Homeownership often conveys a status and commitment to place that impacts Census participation. Data consistently show that renters have net undercount rates while homeowners have net overcounts. Examination of differential undercounts by tenure is also a reflection of socioeconomic status since homeowners generally have higher incomes than renters.

In Chap. 13, theories and data on why people are missed in the Census are examined. The material in this Chapter includes broad frameworks for understanding why people are missed in the Census as well as several individual mechanisms that may result in someone being left out of the Census count. 
Given the pervasive and long-standing differential undercount patterns, it is worth noting efforts the Census Bureau has made to reduce differential undercounts. In Chap. 14, some of the key activities the Census Bureau has utilized in the past few decades to improve Census coverage and reduce differential undercounts are reviewed.

In Chap. 15, some of the key issues surrounding the upcoming 2020 Census are examined. Some of the major developments regarding 2020 Census planning are discussed and I offer some thoughts about the implications these have for Census coverage in the 2020 Census.

Finally, in Chap. 16 I offer a brief summary of key findings and some of their implications.

Most of the focus in this book is on data from the 2010 Census with some examination of long-term trends when the data are available and appropriate. The reality is many of the groups that have high net undercounts in the 2010 Census have experienced problems with Census coverage for many decades. I feel it is important to recognize that history.

\subsection{Summary}

While the Census Bureau tries very hard to count every person in the country some people are always missed, and some groups are missed at a higher rate than others. The net undercount reflects the difference between people missed and people counted twice. Some groups have higher net undercount rates than others in the Census and some groups have higher omissions rates than other groups. This book focuses primarily on groups with relatively high net undercounts and high omissions rates and to a lesser extent on groups with relatively high net overcounts.

\section{References}

Blank, R. (2012). Statement by Deputy U.S. Commerce Secretary Rebecca Blank on Release of the Data Measuring Census Accuracy. May 22, 2012.

Bruce, A., \& Robinson, J. G. (2003). The planning database: Its development and use as an effective tool in census 2000. Paper presented at the Annual Meeting of the Southern Demographic Association, Arlington, VA.

de la Puente, M. (1993). Using ethnography to explain why people are missed or erroneously included by the census: Evidence from small area ethnographic research. U.S. Census Bureau

Erdman, C., \& Bates, N. (2017). The low response score (LRS) a metri to locate, predict, and manage hard-to-survey populaiton. Public Opinion Quarterly, 81(1), 144-156.

Fay, R. E, Passel, J. S., Robinson, J. G., \& Cowan, C. D. (1988). The coverage of the population in the 1980 census. U.S. Census of Population and Housing, Evaluation, and Research Reports, PHC80-E4, U.S Census Bureau, Washington, DC. 
Fernandez, L., Shattuck, R., \& Noon, J. (2018). The use of administrative records and the American Community Survey to study the characteristics of undercounted young children in the 2010 Census. Center for Administrative Records Research and Applications, CARRA Working Paper Series, Working Paper Series \#2018-05, U.S Census Bureau. Washington, DC.

Govern, K., Coombs, J., \& Glorioso, R. (2012). 2010 census coverage followup assessment report. U.S. Census Bureau 2010 Census Program for Evaluation and Experiments, No. 244, March 29.

Jensen, E., Benetsky, M., \& Knapp, A. (2018). A sensitivity analysis of the net undercounts for young Hispanic children in the 2010 census. In Poster at eh 2018 Population Association of American Conference, Denver, Colorado April 25-28 downloaded May 5, 2108, at https://paa. confex.com/paa/2018/meetingapp.cgi/Paper/20826.

King, H., Ihrke, D., \& Jensen, E. (2018). Subnational estimates of net coverage error for the population aged 0 to 4 in the 2010 census. In Paper present the 2018 Population Association of American Conference, April 25-28, Denver Colorado, Downloaded May 6, 2018 https://paa.confex.com/ paa/2018/meetingapp.cgi/Paper/21374.

Kissam, E. (2017). Differential undercount of Mexican immigrant families in the U.S. census. Statistical Journal of the International Association of Official Statistics, 797-816. https://doi. org/10.3233/sji-170366m (IOS Press).

Letourneau, E. (2012). Mail response/return rates assessment. 2010 Census Planning Memorandum Series, No. 198, U.S. Census Bureau, Washington, DC.

Mayol-Garcia, Y., \& Robinson, G. (2011). Census 2010 counts compared to the 2010 population estimates by demographic characteristics. In Poster presented at the Southern Demographic Association Conference, October, Tallahassee, FL.

O'Hare, W. P. (2015). The undercount of young children in the U.S. Decennial Census. Springer Publishers.

O'Hare, W. P. (2016). Who lives in hard-to-count neighborhoods? International Journal of Social Science Studies, 4(4), 43-55.

Raymondo, J. C. (1992). Population estimation and projection: Methods for marketing, demographic, and planning personnel.

Robinson, G, J., \& Adlaka, A. (2002). Comparison of A.C.E. revision II results with demographic analysis, DSSD A.C.E. Revision II Estimates Memorandum Series \#PP-41, December 31, 2002, U.S. Census Bureau, Washington, DC.

Robinson, G. J., Bashir. A., Das Dupta, P., \& Woodward, K. A. (1993). Estimates of population coverage in the 1990 United States U.S. Decennial Census based on demographic analysis. Journal of the American Statistical Association, 88(423), 1061-1071.

Robinson, J. G. (2010). Coverage of population in Decennial Census 2000 based on demographic analysis: The history behind the numbers. Decennial Census Bureau, Working Paper No. 91, available online at http://www.Census.gov/population/www/documentation/twps0091/twps0091.pdf.

Schwede, L. (2003). Complex households and relationships in the Decennial Census and in ethnographic studies of six racelethnic groups. Final Census 2000 Testing and Experimentation Program Report. Available at: http://www.Census.gov/pred/www/rpts/Complex\%20Households\% 20Final\%20Report.pdf.

Schwede, L. (2004). Household types and relationships in six race/ethnic groups: Conceptual and methodological issues. In Proceedings of the American Statistical Association Section on Survey Research Methods (pp. 4991-4998). Available at: www.amstat.org/sections/srms/proceedings/ y2004/Files/Jsm2004-000772.pdf.

Schwede, L. (2006). Who lives here? Complex ethnic households in America. In Complex Ethnic Households in America. Rowman and Littlefield.

Schwede, L. (2007). A new focus: Studying linkages among household structure, racelethnicity, and geographical levels, with implications for census coverage. SRD Report RSM 2007/38. Abstract available at: http://www.Census.gov/srd/www/abstract/rsm2007-38.html. 
Schwede, L., \& Terry, R. (2013). Comparative ethnographic studies of enumeration methods and coverage across racelethnic groups. 2010 Census Program for Evaluations and Experiments Evaluation. 2010 Census Planning Memoranda Series, No. 255. March 29, 2013. http://www.Census.gov/2010Census/pdf/comparative_ethnographic_studies_ of_enumeration_methods_and_coverage_across_race_and_ethnic_groups.pdf.

Schwede, L., Terry, R., \& Hunter, J. (2014). Ethnographic evaluations on coverage of hard-tocount minority in the US Decennial Censuses. In R. Tourangeau, B. Edwards, T. P. Johnson, K. M. Wolter, \& N. Bates (Eds.), Hard-to-survey populations (pp. 293-315). Cambridge, MA: Cambridge University Press.

Tourangeau, R., Edwards, B., Johnson, T. P., Wolter, K. M., \& Bates, N. (2014). Hard-to-survey populations. Cambridge, MA: Cambridge University Press.

U.S. Census Bureau. (1974). Estimates of coverage of population by sex, race and age: Demographic analysis, 1970 U.S. Decennial Census of Population and Housing, Evaluation and Research Program, PHC (E)-4.

U.S. Census Bureau. (2012). 2010 components of census coverage for race groups and hispanic origin by age, sex, and tenure in the United States. DSSD 2010 Census Coverage Measurement Memorandum Series \#2010-E-51, U.S. Census Bureau, Washington, DC.

U.S. Census Bureau. (2016). Developing an integrated communication strategy: Select topics in international census. U.S. Census Bureau, Washington, DC.

U.S. Census Bureau. (2017a). 2020 census integrated communications plan (Version 1.0) 6/2/2017. U.S. Census Bureau Washington, DC.

U.S. Census Bureau. (2017b). 2020 Census program memorandum series: 2017.17, 2020 Census decision to change the name of the coverage measurement survey to the post-enumeration survey, September 14 .

U.S. General Accounting Office. (2003). 2000 census: Coverage measurement programs' results, costs, and lessons learned. Report GA)-03-287, U.S. General Accounting Office, Washington, DC.

Velkoff, V. (2011). Demographic evaluation of the 2010 census. Paper presented at the 2011 Population Association of America Annual Conference, March, Washington, DC.

Williams, J. D. (2012). The 2010 Decennial Census: Background and issues. CRS Report for Congress, Congressional Research Services, 7-5700, R4055.

Word, D. L. (1997). Who responds/ who doesn't? Analyzing variation in mail response rates during the 1990 census. Population Division Working Paper No. 19, U.S. Census Bureau, Washington, DC.

Open Access This chapter is licensed under the terms of the Creative Commons Attribution 4.0 International License (http://creativecommons.org/licenses/by/4.0/), which permits use, sharing, adaptation, distribution and reproduction in any medium or format, as long as you give appropriate credit to the original author(s) and the source, provide a link to the Creative Commons license and indicate if changes were made.

The images or other third party material in this chapter are included in the chapter's Creative Commons license, unless indicated otherwise in a credit line to the material. If material is not included in the chapter's Creative Commons license and your intended use is not permitted by statutory regulation or exceeds the permitted use, you will need to obtain permission directly from the copyright holder.

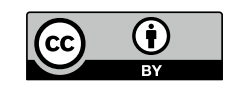

